\title{
Theoretical and Practical Evaluation of Plastic Deformation and Straining Throughout Cupping the Shells of Domestic LPG Cylinders
}

\author{
Dr. Aziz H. Al - Hilfi, $\quad$ Mohammed H. Salih (M.Sc. Mech. Engg.) \\ Department of Mechanical Engineering \\ College of Engineering/ University of Basrah
}

\begin{abstract}
Summary
This paper covers the theoretical and practical evaluation of straining which arise due to stressing, and plastic deformation during the deep drawing process of the production of the shells for LPG cylinders, as well as the process description and application. Therefore the study includes experimental work in the field of metal drawing in stages for different depths to tabulate the radial metal movement and changes in shell thickness and diameter. As the annealing treatment has an important role in the production sequence, so samples of metal used in producing the domestic LPG cylinder were heat treated in different situations to study the influence of an annealing operation on the metal (its microstructure, metallurgical, and mechanical properties).
\end{abstract}

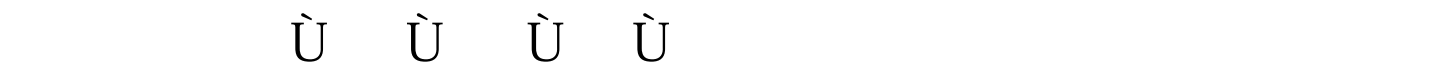

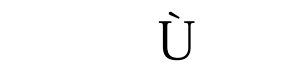

\author{
řŰ UF低
}

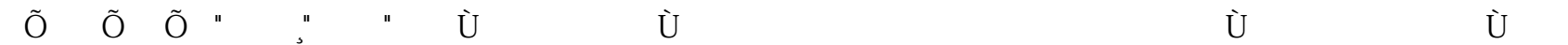

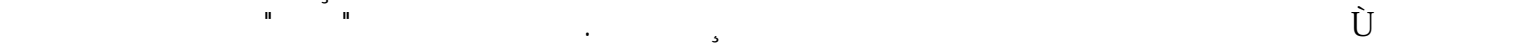

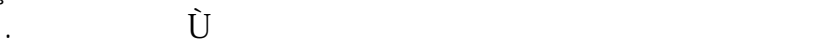

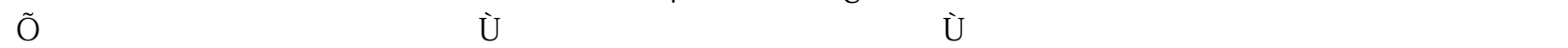

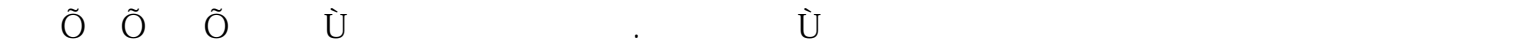

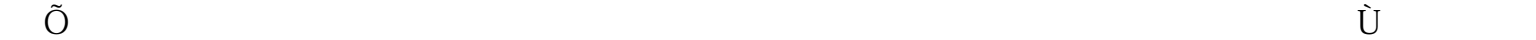

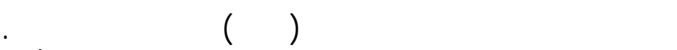

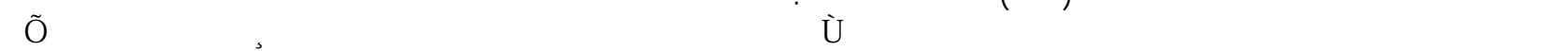

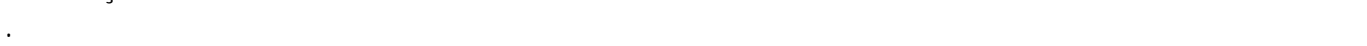




\section{Al- Rafidain Engineering $\quad$ Vol. $14 \quad$ No. $1 \quad 2006$}

\section{Introduction:}

In sheet metal forming, the material is affected by many forces because of the pressing and forcing operations that are used, such that the blank must take the form of the punch and die.

As a result the material will be strained, and its behavior differs from one region to another because of the compression and stretching throughout the cupping operation and shows a thickness variation along the cylinder wall.

2. Evaluation of Strains in the Material of the Blank:

At the rim of the blank, i. e. when $\mathrm{R}=\mathrm{b}$, see Fig. (1) the blank is in a state of uniaxial compression stress, i.e. $\left(\sigma_{\mathbf{r}}\right)_{\mathbf{b}}=0$.

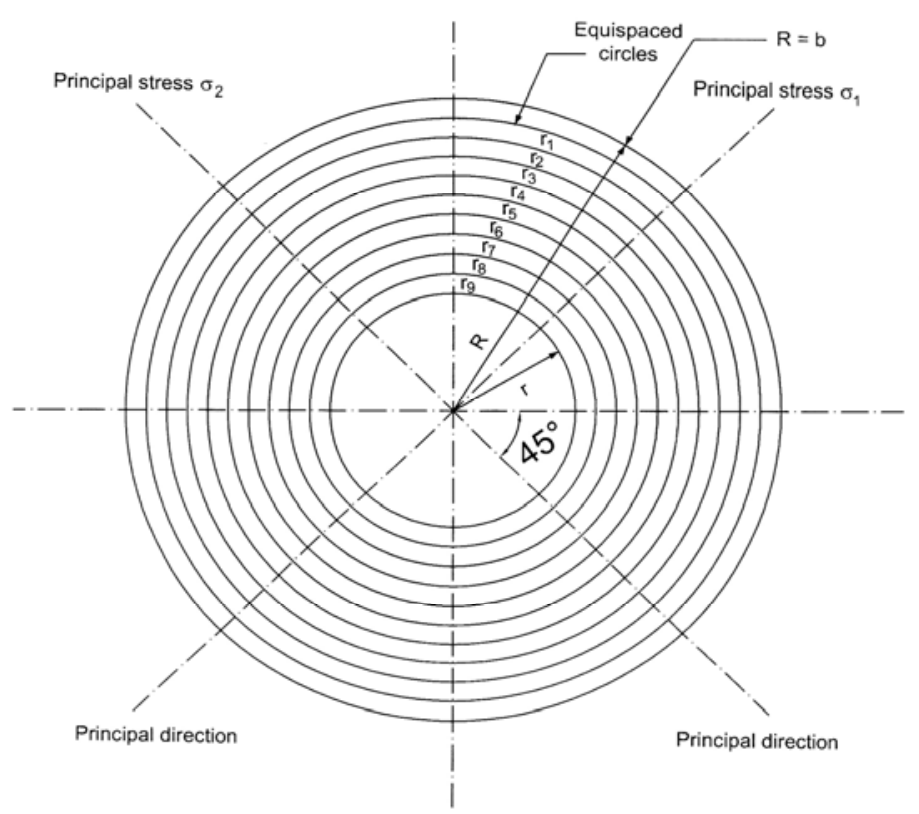

Fig. (1) The state of uniaxial stress acting at the rim of the blank and experimental Hence the state of strain is such that $[1,2]$ :

Hence the state of strain is such that $[1,2]$ :

$\varepsilon_{\mathbf{t}}=\varepsilon_{\mathbf{r}}=-\frac{1}{2} \varepsilon_{\theta}$

$\varepsilon_{\theta}=\ln \left(\frac{\mathrm{r}}{\mathrm{r}_{\circ}}\right)$

$\varepsilon_{\mathrm{t}}=\ln \left(\frac{\mathrm{t}}{\mathrm{to}}\right)$

samples of blanks that are drawn to different depths.

Where: $\varepsilon_{\mathbf{r}}=$ (radial strain), $\varepsilon_{\boldsymbol{\theta}}=($ circumferential strain $)$ and $\varepsilon_{\mathbf{t}}=($ thickness strain $)$ are the principal strains. Therefore, the effective strain $(\varepsilon)$ is given by 
the equation (4) due to von Mises - Hencky (the distortion - energy) theory as follows:

$$
\varepsilon^{\prime}=\frac{\sqrt{2}}{3} \sqrt{\left(\varepsilon_{\mathrm{r}}-\varepsilon_{\theta}\right)^{2}+\left(\varepsilon_{\theta}-\varepsilon_{\mathrm{t}}\right)^{2}+\left(\varepsilon_{\mathrm{t}}-\varepsilon_{\mathrm{r}}\right)^{2}}
$$

Substituting equation (1) into the equation (4) for the effective strain, then,

$$
\begin{array}{r}
\varepsilon^{\prime}=\frac{\sqrt{2}}{3} \sqrt{\left(\frac{3}{2} \varepsilon_{\theta}\right)^{2}+\left(\frac{3}{2} \varepsilon_{\theta}\right)^{2}} \\
\varepsilon^{\prime}=\varepsilon_{\theta}
\end{array}
$$

From the analysis of the total effective strains in the foregoing equations, the effective stress $\left(\sigma_{c}\right.$ - compressive flow stress) developed in the material during the operation has been determined from the knowledge of the stress - strain relations formula of the material, [3], namely:

$$
\text { (6) } \sigma_{\mathrm{c}}=\mathrm{c}\left(\varepsilon^{\prime}\right)^{\mathrm{n}}
$$

Then the actual tensile stress developed in the wall of the drawn cup $\left(\sigma_{t}\right)$ has been evaluated from the equation

$$
\sigma_{\mathrm{t}}=\frac{(\mathrm{D}-\mathrm{d})}{\mathrm{d}} \sigma_{\mathrm{c}},[2] \text {. }
$$

The value of effective strain is used for the evaluation of the tensile stress developed in the material during the drawing process, then,

$$
\sigma_{t}=c\left(\varepsilon^{\prime}\right)^{n} \frac{(D-d)}{d}
$$

Where: $\mathrm{c}=$ strength coefficient.

$$
\begin{aligned}
& \mathrm{n}=\text { Strain }- \text { hardening exponent. } \\
& \mathrm{D}=\text { blank diameter, and } \\
& \mathrm{d}=\text { cup diameter }
\end{aligned}
$$

3. Mechanism of the plastic deformation in sheet metal forming (SMF):

The domestic LPG cylinders are manufactured by a deep drawing process, which is one of most familiar operations for cold working of metals. During the manufacturing operation the metal will be subjected to high loads and a permanent (inelastic) distortion under the applied stresses which strain the material beyond its elastic limit. After this occurs the metal is said to be plastically deformed. The deformation is accompanied by changes in the internal state of the metal, involving distortion of the crystal structure. As distortion precedes the resistance of the metal to deformation generally increases, while there is a corresponding reduction in the capacity to deform [4]. The behavior of a metal under plastic deformation and the mechanism by which it occurs are of essential interest in perfecting the working operation.

Much information about the mechanism of plastic deformation can be obtained through studying the behavior of a single crystal under stress and later applying this knowledge to a polycrystalline material. Plastic

deformation may take place by slip, twinning or a combination of both methods [5]. 


\section{Process description and application:}

Deep drawing operation is one of the cold working operations of sheet metal forming (SMF) in which a sheet metal (blank) is formed between the die and punch (without any metal removal), where the punch and die have opposite edges to each other. During the process, as the punch advances the deforming blank takes the form of the punch. And at the end of the operation it assumes the shape of the space between the die and the punch. When the metal is bent over and wrapped around the punch nose, a plastic deformation will occur and different types of forces will be involved as shown in Fig. (2), the outer portion of the sheet metal moves gradually towards the center of blank.

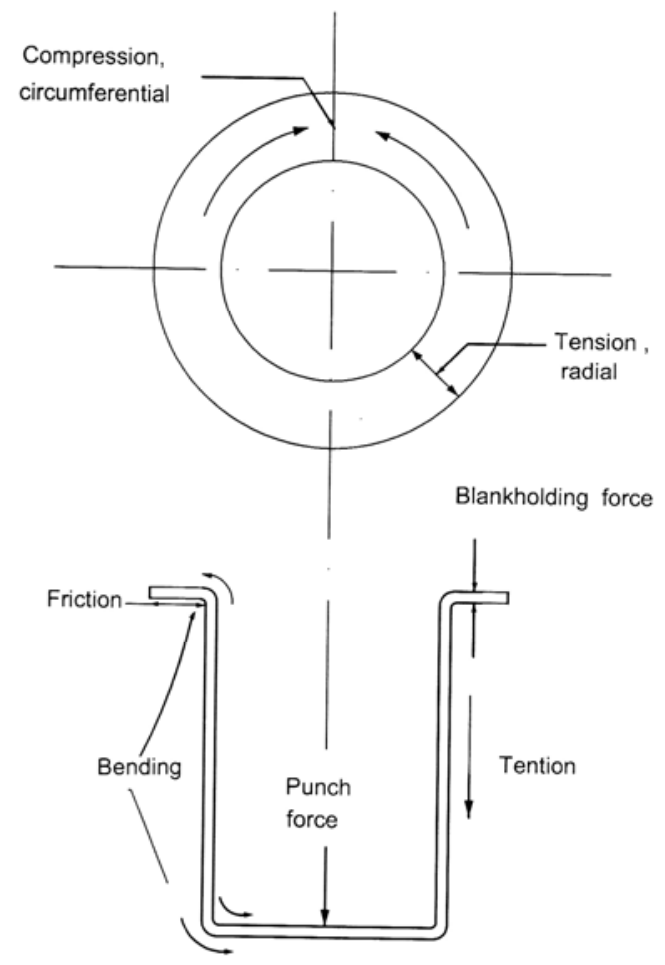

Fig. (2) Forces involved in metal flow during cupping.

As illustrated in Fig. (3), the regions that undergo different types of deformations [6], are as follows:

The flat portion of the blank (flange), which has not, yet entered the die cavity, is subjected to a tensile stress since the punch is pulling the blank into the die cavity. As the metal moves into the die the blank diameter is decreased. A compressive stress acts in the tangential or hoop direction, which can lead to wrinkling of the flange portion of the blank. Therefore a hold down plate (blank holder) is used and by an appropriate blank holding force 
the flange wrinkling can be prevented. However a friction force arises which restrains a blank flow into the die.

The portion of the blank being drawn into the die cavity (the wall region of a shell), is subjected to longitudinal and tangential or hoop tensile stresses since the shell is held tightly on the punch because of its contraction due to the tensile stresses in the shell wall. It can be concluded that there is a complicated stress state at the die shoulder region as the compressive hoop stress on the flange changes to a tensile stress in the tangential direction in the shell wall.

At the region of contact between the shell and the punch bottom, the stress state is of less concern since deformation is less extreme and failure is less likely here.

Due to the different forces acting on the sheet metal, thickening and thinning in the wall of the finished part will occur.
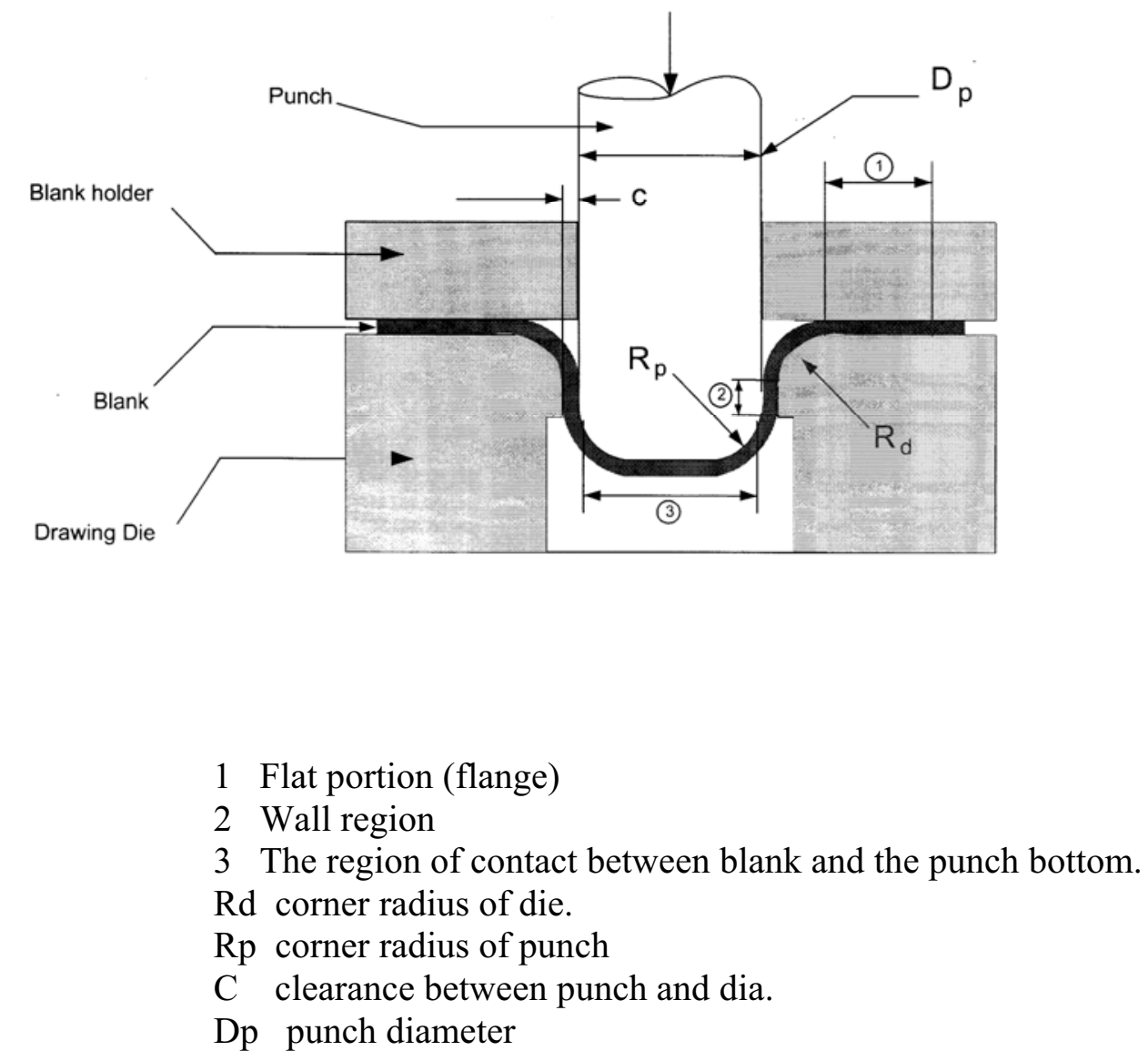

Fig. (3) The configuration of the deep drawing process. 


\section{Al- Rafidain Engineering $\quad$ Vol. $14 \quad$ No. $1 \quad 2006$}

\section{Experimental work:}

Since the aim was to investigate the method of straining in the material during the deep drawing process, and then estimate the deep drawing load on the basis of the total effective strain. For this purpose concentric circles and radial lines are scribed at regular spacing on nine standard blank samples of the metal. See Fig. (1).

Thereafter the blanks were subjected to a controlled deep drawing process progressively at different stages by a hydraulic press. Fig. (4) shows the resulting samples produced, which were progressively drawn to different depths. In order to achieve the strain analysis operation, the following procedure is developed as outlined below:

(1) For every sample the radius of all circles before the drawing process, namely: $r, r_{1}$, ... $r_{9}$, and $\mathrm{R}$ are measured and recorded, where $r$ is the shell radius, and $\mathrm{R}$ is the radius of the blank.

(2) From the simple theoretical analysis that depends on equations (4, 5, 6, 7 and 8), the circumferential strain $\left(\varepsilon_{\theta}\right)$, and the thickness strain $\left(\varepsilon_{t}\right)$ have been evaluated. The true thickness strains $\left(\varepsilon_{t}\right)$ in the sheet metal blank have been measured by means of the set up developed by the authors as shown in Fig. (5). It consists of a simple clamping fixture device, micrometer, and a vernier. The thickness and radius measurements and calculations are listed in tables (1), (2), (3), (4), (5) and (6).

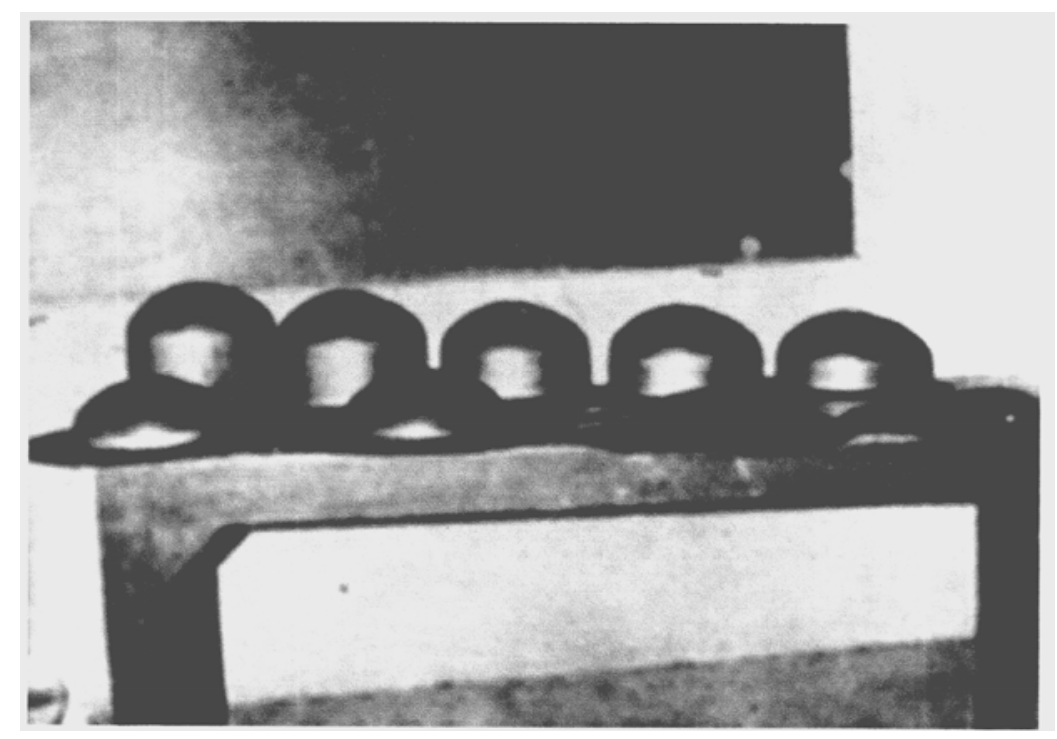

Fig.(4) Different samples have been drawn to the different depths. 


\section{Al-Hilfi: Theoretical and Practical Evaluation of Plastic Deformation}

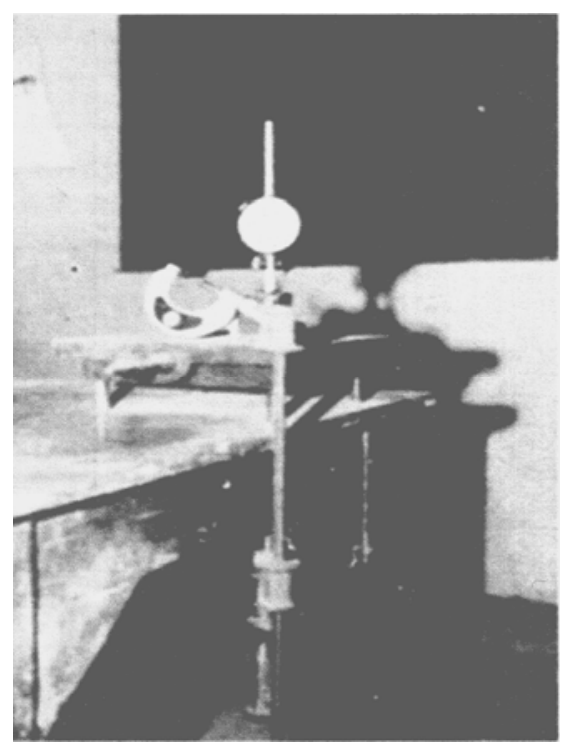

Fig, (5) Setup for measuring the thickness of drawn shell.

Table (1) Radius measurements of the samples at different drawing stages.

\begin{tabular}{|c|c|c|c|c|c|c|c|c|c|c||}
\hline \multirow{2}{*}{$\begin{array}{c}\text { Radii } \\
\mathrm{mm}\end{array}$} & \multirow{2}{*}{ Blank } & \multicolumn{10}{|c||}{ Sample Number } \\
\hline & 1 & 2 & 3 & 4 & 5 & 6 & 7 & 8 & 9 \\
\hline $\mathrm{R}$ & 282 & 274.4 & 271.35 & 253.1 & 252 & 226.6 & 210.8 & 203.2 & 177.65 & 156.75 \\
\hline$r_{1}$ & 268.8 & 260.65 & 257.45 & 238.45 & 237.45 & 211.6 & 195.45 & 187.45 & 160.2 & \\
\hline$r_{2}$ & 255.6 & 247.45 & 244.2 & 225 & 223.65 & 196.5 & 179.5 & 176.65 & & \\
\hline$r_{3}$ & 242.4 & 233.95 & 230.85 & 210.75 & 209.75 & 181.15 & 163.15 & & & \\
\hline$r_{4}$ & 229.2 & 220.6 & 217.5 & 196.5 & 195.45 & 165.1 & & & & \\
\hline$r_{5}$ & 216 & 208 & 204.15 & 182.05 & 180.85 & & & & & \\
\hline$r_{6}$ & 202.8 & 194.55 & 190.8 & & & & & & & \\
\hline$r_{7}$ & 189.6 & 181.55 & 177.45 & & & & & & & \\
\hline$r_{8}$ & 176.4 & & & & & & & & & \\
\hline$r_{9}$ & 163.2 & & & & & & & & & \\
\hline$r$ & 150 & & & & & & & & & \\
\hline \hline
\end{tabular}

S, wher e the diam eter of blank is: $564 \mathrm{~m}$

$\mathrm{m}$. $r=$ shell radiu s, wher e the LPG cylin der diam eter is: $300 \mathrm{~mm}$ 
$\begin{array}{lccc}\text { Al- Rafidain Engineering } & \text { Vol. } 14 & \text { No. } 1 & 2006\end{array}$

Table (2) Thickness measurements of the sample at different drawing stages

\begin{tabular}{||c|c|c|c|c|c|c|c|c||}
\hline \multirow{2}{*}{$\begin{array}{c}\text { Thickness } \\
\mathrm{mm}\end{array}$} & \multirow{2}{*}{ Blank } & \multicolumn{7}{|c||}{ Sample Number } \\
\cline { 3 - 9 } & 1 & 2 & 3 & 4 & 5 & 6 & 7 \\
\hline $\mathrm{T}_{1}$ & 3.2 & 3.84 & 3.29 & 3.543 & 3.57 & 3.772 & 3.7084 & 3.62 \\
\hline $\mathrm{T}_{2}$ & 3.2 & 3.404 & 3.315 & 3.5687 & 3.594 & 3.785 & 3.7211 & 3.58 \\
\hline $\mathrm{T}_{3}$ & 3.2 & 3.391 & 3.302 & 3.556 & 3.594 & 3.772 & 3.6576 & 3.53 \\
\hline $\mathrm{T}_{4}$ & 3.2 & 3.391 & 3.302 & 3.5306 & 3.5687 & 3.747 & & \\
\hline $\mathrm{T}_{5}$ & 3.2 & 3.391 & 3.302 & 3.48 & 3.5687 & & & \\
\hline $\mathrm{T}_{6}$ & 3.2 & 3.391 & 3.302 & 3.505 & 3.53 & & & \\
\hline \hline
\end{tabular}

Table ( 3 ) Circumferential Strain, $\varepsilon_{\boldsymbol{\theta}}=\ln \mathrm{r} / \mathrm{r}_{\mathbf{0}}$ and Effective Strain

\begin{tabular}{|c|c|c||c||c|c|c||c||}
\hline \multirow{2}{*}{$\varepsilon=\varepsilon_{\theta}$} & \multicolumn{6}{l}{ Sample Number } \\
\cline { 2 - 7 } & 1 & 2 & 3 & 4 & 5 & 6 & 7 \\
\hline \hline$\varepsilon_{\theta 1}$ & -0.0273 & -0.0385 & -0.108 & -0.1125 & -0.2187 & -0.291 & -0.327 \\
\hline$\varepsilon_{\theta 2}$ & -0.0308 & -0.04314 & -0.120 & -0.1244 & -0.240 & -0.3186 & -0.360 \\
\hline \hline$\varepsilon_{\theta 3}$ & -0.0327 & -0.04562 & -0.1275 & -0.1335 & -0.263 & -0.3534 & -0.404 \\
\hline$\varepsilon_{\theta 4}$ & -0.0355 & -0.0488 & -0.140 & -0.1447 & -0.2912 & -0.396 & \\
\hline$\varepsilon_{5}$ & -0.0385 & -0.0524 & -0.154 & -0.160 & -0.328 & & \\
\hline \hline$\varepsilon_{\theta 6}$ & -0.0361 & -0.0564 & -0.171 & & & & \\
\hline
\end{tabular}

* The ( - ) sign of the numbers indicates compression 
Table ( 4 ) Thickness Strain, $\varepsilon_{\mathbf{t}}=\ln \mathrm{t} / \mathrm{t}_{\mathbf{o}}$

\begin{tabular}{||c|c|c|c|c|c|c|c||}
\hline \hline \multirow{2}{*}{$\mathrm{T}$} & \multicolumn{7}{|c||}{ Sample Number } \\
\cline { 2 - 8 } & 1 & 2 & 3 & 4 & 5 & 6 & 7 \\
\hline 1 & 0.18232 & 0.02774 & 0.1018 & 0.1094 & 0.1644 & 0.1475 & 0.1232 \\
\hline 2 & 0.0617 & 0.03522 & 0.1095 & 0.1161 & 0.1678 & 0.15087 & 0.1126 \\
\hline 3 & 0.058 & 0.0314 & 0.1055 & 0.1166 & 0.1644 & 0.1337 & 0.0983 \\
\hline 4 & 0.058 & 0.0314 & 0.0983 & 0.109 & 0.1577 & & \\
\hline 5 & 0.058 & 0.0314 & 0.084 & 0.0983 & & & \\
\hline 6 & 0.058 & 0.0314 & 0.0911 & & & & \\
\hline \hline
\end{tabular}

Table (5) Comparison Between Measured and Calculated $\varepsilon_{\mathbf{t}}$

\begin{tabular}{||c|c|c|c|c|c|c|c|c||}
\hline \hline $\begin{array}{c}\text { Thickness } \\
\varepsilon_{t} \text { Strain }\end{array}$ & \multirow{2}{*}{ Blank } & \multicolumn{7}{|c||}{ Stage of Drawing } \\
\cline { 3 - 9 } & 1 & 2 & 3 & 4 & 5 & 6 & 7 \\
\hline $\begin{array}{c}\text { Measured } \\
\varepsilon_{t}\end{array}$ & 0 & 0.0793 & 0.0314 & 0.0983 & 0.1096 & 0.1637 & 0.144 & 0.1112 \\
\hline $\begin{array}{c}\text { Calculated } \\
\varepsilon_{t}\end{array}$ & 0 & 0.0168 & 0.0237 & 0.0684 & 0.0710 & 0.1341 & 0.1371 & 0.1763 \\
\hline
\end{tabular}

Table ( 6 ) Compressive Flow Stress $\sigma_{\mathbf{c}}$, Tensile Stress $\sigma_{\mathbf{t}}$, and Drawing Load $\mathrm{L}_{\mathbf{D}}$

\begin{tabular}{||c|c|c|c||}
\hline \hline Stage No. & $\begin{array}{c}\sigma_{c}=c\left(\varepsilon^{\prime}\right)^{n} \frac{(D-d)}{d} \\
\mathrm{kN} / \mathrm{m}^{2}\end{array}$ & $\begin{array}{c}\sigma_{\mathrm{t}}=\frac{(\mathrm{D}-\mathrm{d})}{\mathrm{d}} \\
\mathrm{kN} / \mathrm{m}^{2}\end{array}$ & $\begin{array}{c}\mathrm{L}_{\mathrm{D}} \\
\mathrm{kN}\end{array}$ \\
\hline Blank & Zero & Zero & Zero \\
\hline 1 & 441976.87 & 366546.13 & 1105.474 \\
\hline 2 & 465409.94 & 376516.64 & 1135.544 \\
\hline 3 & 543268.63 & 373406.62 & 1126.164 \\
\hline 4 & 546512.52 & 371628.51 & 1120.802 \\
\hline 5 & 603815.69 & 308348.5 & 930 \\
\hline 6 & 630247.67 & 255460.36 & 770.448 \\
\hline 7 & 641576.64 & 227545.8 & 686.26 \\
\hline
\end{tabular}


\begin{tabular}{llll} 
Al- Rafidain Engineering & Vol. 14 & No. 1 & 2006 \\
\hline
\end{tabular}

\begin{tabular}{||c||c||c|c|c|c||}
\hline $\begin{array}{c}\text { Annealing } \\
\text { temperature } \\
{ }^{\circ} \mathrm{C}\end{array}$ & $\begin{array}{c}\text { Time in } \\
\text { minutes }\end{array}$ & $\begin{array}{c}\text { Yield } \\
\text { strength. } \\
\mathrm{N} / \mathrm{mm}^{2}\end{array}$ & $\begin{array}{c}\text { imate } \\
\text { strength. } \\
\mathrm{N} / \mathrm{mm}^{2}\end{array}$ & $\begin{array}{c}\text { Elongation } \\
\text { percentage } \\
\text { in 20 mm }\end{array}$ & $\begin{array}{c}\text { Grain size. } \\
\mathrm{mm} .\end{array}$ \\
\hline \hline No & - & 235.27 & 413.503 & 35 & 0.015 \\
\hline 880 & 5 & 106.94 & 320.821 & 40 & 0.0356 \\
\hline 880 & 15 & 99.81 & 295.87 & 46.5 & 0.042 \\
\hline 900 & 5 & 92.682 & 288.74 & 45.5 & 0.0372 \\
\hline 900 & 15 & 91.256 & 285.175 & 39 & 0.038 \\
\hline 920 & 5 & 85.552 & 283.75 & 38.5 & 0.0444 \\
\hline 920 & 15 & 79.85 & 270.916 & 37.5 & 0.0517 \\
\hline
\end{tabular}

Table (7)

Mechanic al and

metallurgi cal properties of annealed samples. 5. Practical study of thinning and thickenin

$\mathrm{g}$ in the drawn shell:

The experimental work was conducted to investigate the thinning and thickening behavior in the wall thickness of the produced part where a longitudinal cross section of the shell has been taken as shown in Fig. (6). The thickness was, then measured along the wall of the sectioned part in several places point starting from the extreme end of the shell (rim of the shell) up to the bottom center of the shell.

The analysis of the results obtained in this experimental work is as follows:

(a) There is a thickening in the wall of the shell such that the thickness appears to be more than the original value, which is equal to $3.2 \mathrm{~mm}$ of the thickness of the sheet metal blank, $(4.02 \mathrm{~mm}$ at the end of the shell). This behavior is possible in the flange region, i.e., the region of blank holder and the die, where compressive forces stress the material. The wall begins thinning as the metal moves towards the center of the shell where it takes the form of the punch. It appears thinner in its thickness than the original thickness of the blank, $(2.99 \mathrm{~mm}$.) because of the extreme tension in this region especially in the flank of the die and the radii region of the punch.

(b) The thickness values in the produced shell show slight decrease towards the bottom especially in the flank of the die and the radii of the punch, and vice versa.

(c) The metal in the contact region between the shell and the punch bottom shows the values of thickness to be approximately close to the original value of the thickness size of the blank. Because the stress state in this region is of less importance since the plastic deformation is less extreme, therefore it can be concluded that the failure in this region is less likely to occur. But, also, 
there is a slight fluctuation in the size of the thickness; such behavior verifies that there is little plastic deformation in this region.

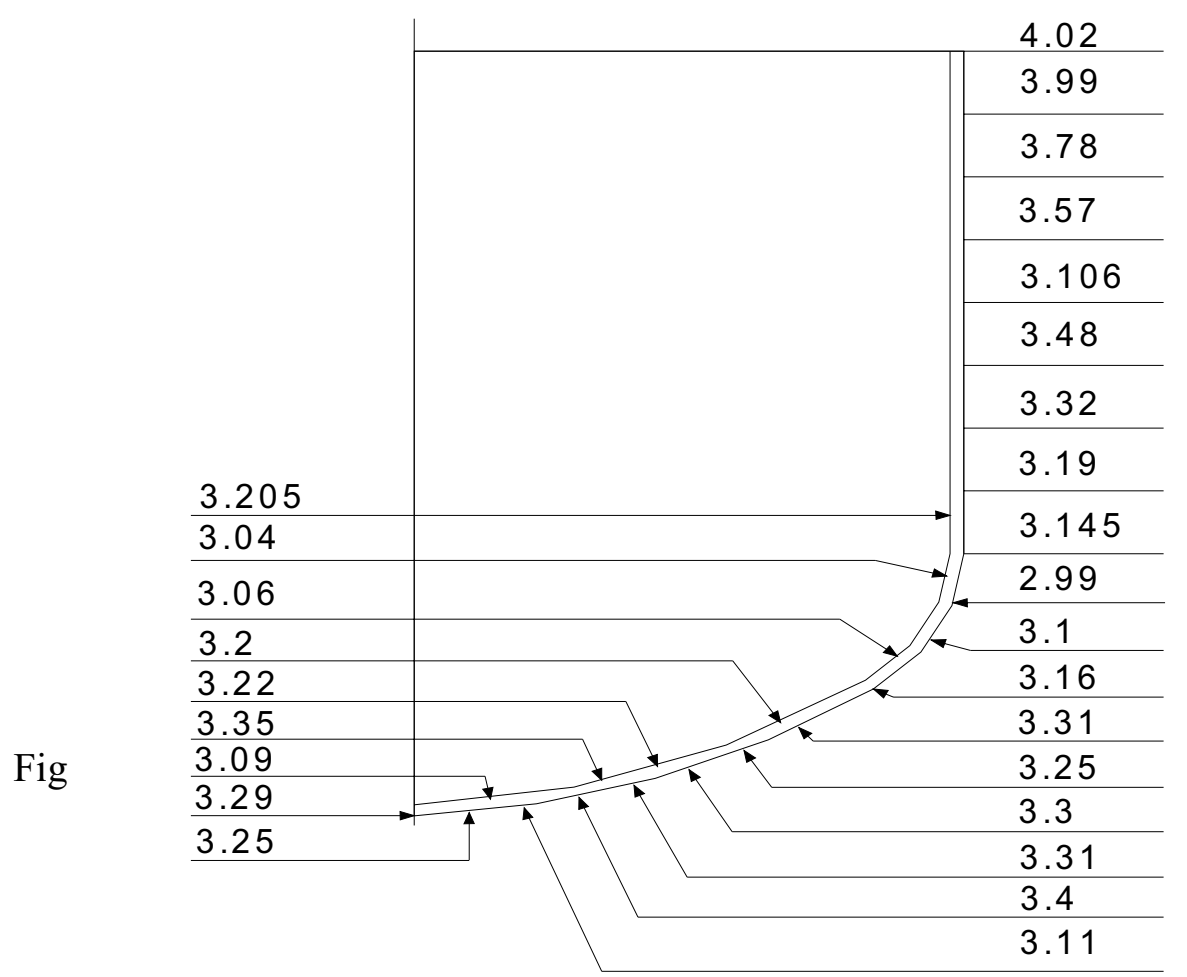

Thickness variation in the wall of deep drawn shell

5.2 Annealing treatment and failure testing:

The production line sequence of manufacturing the domestic LPG cylinders shows that many subsequent processes are related together such that failure in any one of the operations will influence the quality of products and the rate of production. One of the most important operations is the annealing operation, which must be carried out after cupping the two main symmetrical parts and assembly of the cylinder. Therefore, due to the importance of the annealing treatment and its influence on the mechanical and metallurgical properties of a metal, the authors have conducted many experiments for heat treatment of samples of the metal (low alloy steel which have the following chemical composition: $0.15 \% \mathrm{C}$, $0.33 \% \mathrm{Mn}, 0.2 \% \mathrm{Si}, 0.019 \% \mathrm{P}$, and $0.015 \mathrm{~S} \mathrm{Al}-$ killed-special killed) used in manufacturing the LPG cylinders. The experimental procedure is outlined as follows:

The annealing treatments used in these experiments have been carried out in an ordinary electric furnace [HERRMANN - MORITZ (MF2) - French made], 
(Max. temp. $1000^{\circ} \mathrm{C}$, size $9.5 \times 12.5 \times 15$ ) $\mathrm{cm}$ without any protection for surface oxidation and scaling during heating of the specimens. The standard test specimens of the metal are subjected to heat (separately), each specimen for a specific temperature and kept in that annealing

temperature for a specific period of time as shown in table (7). Then the treated specimens are cleaned and etched thoroughly in a careful manner. This is to remove scaling from the surface of each specimen, which is formed due to the annealing operation, and to make visible the many structural characteristics of the

annealed specimens. The etched specimens are, then, transferred for the operation of metallography by the microscope. Microscopic pictures were taken for each specimen in order to study the effect of an annealing operation on the microstructure of the metal after the magnification of (100 times). In addition to study its effect on grain growth and on the grain size throughout different temperatures, at different time periods. The results are shown in table (7) and Fig. (7). The specimens are then subjected to a mechanical failure testing in order to evaluate the mechanical properties of the material. It is worth noting that one specimen of the stock material of the LPG cylinder was not subjected to the annealing treatment. Instead it is inspected microscopically; its microstructure is photographed, and then is subjected to a mechanical failure test in order to compare the material properties before and after annealing.

The estimation of a grain size has been achieved through the estimation of the number of grains per one square inch when the magnification is 100 times.

Then this number is compared with the ASTM standard chart, and hence the size of the grains in the different specimens was determined. The results are shown in table (7)

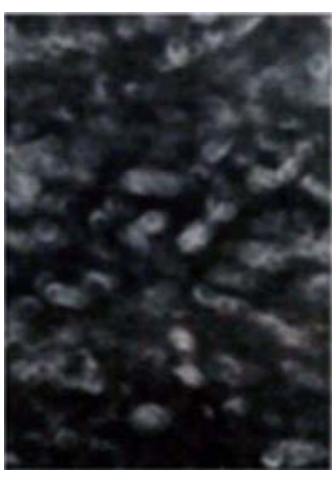

Sample No.1 Ambient temperature, No annealing

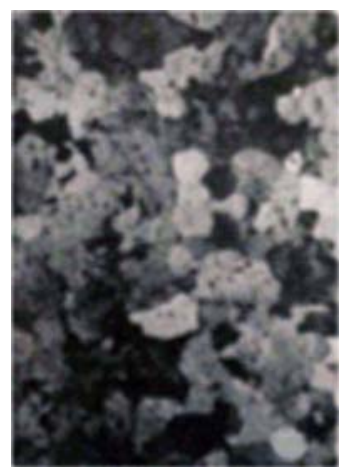

Sample No.2 Annealing temperature $880{ }^{\circ} \mathrm{C}, 5 \mathrm{~min}$. period

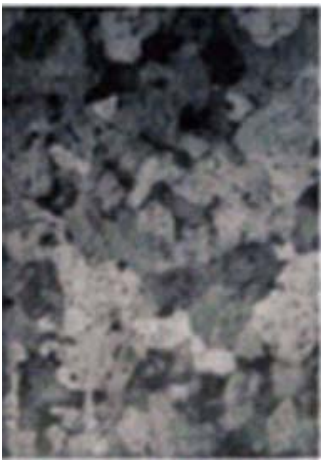

Sample No.3 Annealing temperature $880{ }^{\circ} \mathrm{C}, 15$ min. period

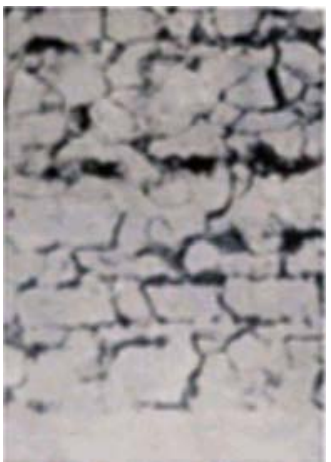

Sample No.4 Annealing temperature $900{ }^{\circ} \mathrm{C}, 5 \mathrm{~min}$. period 


\section{Al-Hilfi: Theoretical and Practical Evaluation of Plastic Deformation}

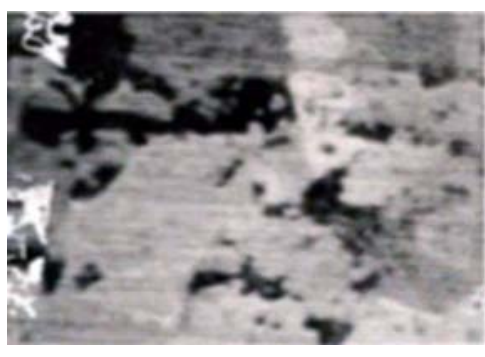

Sample No. 5

Annealing Temperature $900{ }^{\circ} \mathrm{C}, 15$ min. period

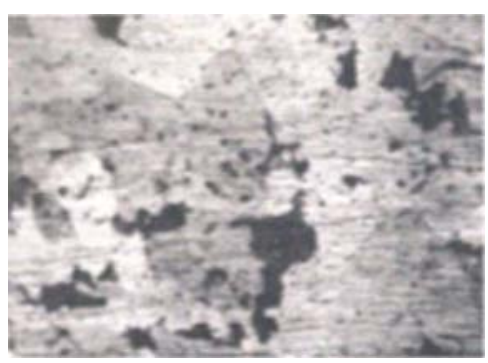

Sample No. 6 Annealing Temperatur $920{ }^{\circ} \mathrm{C}, 5 \mathrm{~min}$. period

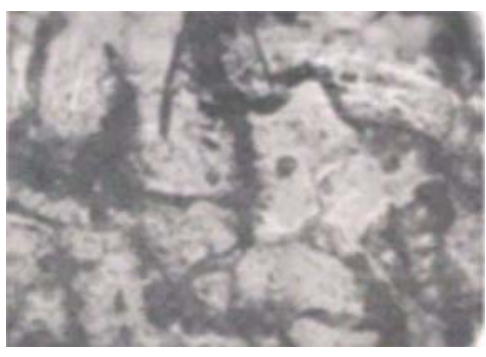

Sample No. 7 Annealing Temperature $920{ }^{\circ} \mathrm{C}, 15 \mathrm{~min}$. period

Fig.(7) : study of Grain size (magnification x(100)

\section{Results and Discussion:}

The results obtained from the samples, which were drawn to different depths, show that there is a gradual increase in the compressive stress $\left(\sigma_{c}\right)$ as the metal moves radially towards the center of the blank. On the other hand there is a gradual decrease in the value of the tensile stress $\left(\sigma_{t}\right)$ as the deep drawing operation proceeds. These two situations of stressing: (compressive and tensile) cause thickening and thinning in the thickness of the wall of the product. The results obtained from the deep drawing load show an increase in the value of the load up to stage number (4) as shown in table (6). Because the flow of the metal is slightly slow, due to the large blank holding area in the flange region and the metal is not wrapped perfectly on the punch bottom the deep drawing load values show the above-mentioned increase. As deep drawing proceeds and the depth of the shell reaches the end limits and the metal slides quickly as it leaves the flange region and becomes free from the blank holder, the deep drawing load will show a rapid decrease in its value. It is obvious from the results listed table (6) that the values of the deep drawing load depend upon the values of the tensile stress of the metal and are proportional with it. Along the stages of drawing the samples an increase in the values of true strain in thickness as well as in the calculated values of the circumferential strain indicate that there is a strain hardening in the metal as the deep drawing process goes on. Table (5), shows that there is a slight difference between the measured (true) and calculated values of the thickness strain since the calculated values are estimated on the basis of some theatrical assumptions, whereas the measured values indicate the true state of the thickness strain.

\section{Discussion of the results obtained from the annealing treatment:}

The results that are shown in table (7) indicate that mechanical properties of the metal when tested before annealing are as follows: 
Yield strength

$$
\begin{array}{ll}
\qquad=235.27 \mathrm{~N} / \mathrm{mm}^{2} & \\
\text { Ultimate strength } & =413.503 \mathrm{~N} / \mathrm{mm}^{2} \\
\text { Elongation percentage in } 20 \mathrm{~mm} & =35 \% \\
\text { Grain size } & =0.015 \mathrm{~mm}
\end{array}
$$

The above characteristics present that the material has very good mechanical and metallurgical properties since its grain size lies within the range of $(0.015-0.02) \mathrm{mm}$ which is an optimum range characterizing the materials of good drawability, such range classify the metal as it has a fine grain. The fine grain materials besides they have a higher strength, they show better resistance to cracking, and they are better for deep drawing, [8].

It shows that by the annealing treatment and metallurgical inspection and presentation as the material is heated up to $\left(880^{\circ} \mathrm{C}\right.$ and held in that

temperature in the furnace for (5 minutes), its yield strength decreases to about half its original value (i.e., before annealing). Such state is observed also in the value of the ultimate strength such that it decreases to about (2/3) its original value and the grain growth is significantly increased to more than (twice) the original grain size, approximately. This situation justifies the ductility of the material. As the changes in annealing conditions take place such that, as the annealing temperature and the period of holding the metal in

that temperature is increased, it can be seen that there is a wide difference between the values of mechanical and metallurgical properties. They show a significant decrease in the mechanical properties and rapid grain growth, where a large increase in grain size is observed. For example, at a temperature of $\left(920^{\circ} \mathrm{C}\right)$ and a period of $(15$ minutes $)$ of holding the specimen in an annealing heat treatment, yield strength of the material becomes about $(1 / 3)$ the original value of the yield strength of material. Whereas the value of the ultimate strength becomes about (2/3) its original value of ultimate strength of material, and the grain size becomes about (3.44) times the original grain size.

The above results also justify that there is a change in crystallization structure in the metal as the annealing condition is changed.

8. Conclusions:

During the forming the LPG cylinder cups by deep drawing, instead of theories and mechanisms of crystal distortion, the metal used for production is plastically deformed and its feature appears in the cylinder wall to be in a state of thickening and thinning at different points. Such phenomenon causes a wavy surface that may lead to wrinkles, and restricts metal movement during the forming operation and affects tools surface and their life. In other regions, it was observed that the metal is thinned and necked and it may show a tendency to failure. To avoid or eliminate such a behavior it is necessary to take a good care in the alignenment and allowances of the clearances between the tools and metal, as well as in adopting proper and adequate loads throughout the process of forming. On the other hand, the selection of suitable metal that has a good response for different loads is an important factor for ease of the operation with minimum defects in the wall of the cylinder. Such possibility can, also, be obtained through mechanical and metallurgical testing of the material. 


\section{Al-Hilfi: Theoretical and Practical Evaluation of Plastic Deformation}

\section{References:}

[1] Crane, E.V.," Plastic Working of Metals". John Wiley \& Sons, Inc., New York 1944. [2] Hoffman, F. \& Sacks, G., "Introduction to Theory of Plasticity for Engineers". McGraw - Hill Book Company.

[3] Shigley J.E, "Mechanical Engineering Design", McGraw - Hill Book Company, 1986.

[4] Trottle, C.R., "An Encyclopaedia of Metallurgy and Materials". [M.S], pp342. Macdonalds and Evans Ltd, 1984.

[5] Avenger, S.H., "Introduction to Physical Metallurgy", McGraw - Hill Book Company, 1974.

[6] Jun Du \& Barney E. Klamecki," The Deep Drawing Process ", Klamecki page, 1998. [7] Gupta R. B., "Production Technology", Satya Prakashan, 1982. 